\title{
Hyperargininemia with Arginase Deficiency
}

\author{
S. D. CEDERBAUM (32), K. N. F. SHAW, E. B. SPECTOR, M. A. VERITY, P. J. SNODGRASS, AND
}

G. I. SUGARMAN

\begin{abstract}
Departments of Psychiatry, Pediatrics, and Neuropathology and the Mental Retardation Research Center, University of California, Los Angeles, School of Medicine and the Children's Hospital of Los Angeles, and the Department of Pediatrics, University of Southern California School of Medicine, Los Angeles, California, and the Department of Medicine, Indiana University School of Medicine and the Medical Service, Indianapolis Veterans Administration Hospital, Indianapolis, Indiana, USA
\end{abstract}

\section{Summary}

A female and a male sibling aged 15 and 8 yr developed almost normally for $3 \mathrm{yr}$, then gradually deteriorated intellectually and physically. Both patients showed marked hyperargininuria (up to 370 times normal), prominent lysinuria, cystinuria, and ornithinuria, and a milder generalized amino aciduria. In plasma, arginine was $600-1000 \mu \mathrm{M}$ (4-7 times normal), but other amino acids were not increased. The levels did not change in response to increased protein intake from $1-3 \mathrm{~g} / \mathrm{kg} / \mathrm{day}$. In cerebrospinal fluid (CSF), arginine was 70-100 $\mu \mathrm{M}$ (3-5 times normal) and numerous other amino acids were also high. Plasma ammonia was generally normal, but rose to $250 \mu \mathrm{g} / \mathrm{dl}$ ( 5 times normal) after increased protein intake and, occasionally, other stresses. The erythrocyte arginase activity level was $<1 \%$ of normal and half normal in the mother and three healthy siblings. White blood cell arginase activity was less than 5\% of the lowest normal control. Liver obtained at open biopsy in the older sibling was deficient in arginase activity $(1.5 \%$ of normal), but had levels of the other four urea cycle enzymes that were within the normal range. Electron microscopic and histochemical studies revealed patchy severe hydropic changes, increased cellular glycogen, normal mitochondria, and dilated endoplasmic reticulum.

\section{Speculation}

The pathogenesis of the neurologic abnormalities in patients with arginase deficiency may in part be the perturbation of intracellular amino acid levels secondary to the elevated levels of arginine.

The urea cycle is the major pathway for the detoxification of ammonia in humans. Two molecules of ammonia generated from protein catabolism are ultimately combined with $\mathrm{CO}_{2}$ to form urea in a 5-step process. Deficiency of arginase, the final enzyme in the cycle, which converts arginine to ornithine and urea, has been reported previously in seven patients: in three German siblings $(5,20-24,26)$; in two first cousins of Puerto Rican descent (19); in a patient of Ashkenazi Jewish origin (3); and in a MexicanAmerican (10). This defect may have occurred in another incompletely studied patient (13).

We present studies of two siblings of Mexican origin, document the deficiency of arginase in white blood cells and liver, and report abnormal levels of 15 amino acids in cerebrospinal fluid, a finding that suggests a general perturbation in amino acid homeostasis in these patients.

\section{CASE REPORTS}

Patient R. U., a 15-yr-old female, is the second of eight liveborn children of healthy nonconsanguineous parents. Pregnancy, delivery, size at birth, and the immediate postnatal period were said to be normal. The patient was irritable beginning in the 4th week of life and development was thought to be on the slow side of normal. By age 3, she was able to walk, run, and speak in phrases and occasional short sentences. At this time, increasing clumsiness was noted, the growth rate diminished, and mental deterioration began. When seen at UCLA at age 6 , she was bilingual (English and Spanish), was able to go to a normal school, but could walk only with the aid of braces. Severe spasticity and hyperreflexia of the lower extremities was noted, and a history of periods of heightened irritability was obtained. She was small for her age, and her height and weight have remained constant for the subsequent $9 \mathrm{yr}$. Since then, physical and intellectual deterioration has been slow and continuous. There was no history of apparent seizures.

The height $(110 \mathrm{~cm})$ and weight $(18.3 \mathrm{~g})$ were far below the third percentile, and the head circumference was $50 \mathrm{~cm}(<$ third percentile). The patient was extremely hirsute, and there was no hepatomegaly. The general physical examination was normal.

The neurologic examination revealed severe psychomotor retardation. She could not speak or understand language, she played at a 1-yr-old level and she was largely oblivious to people or her environment. The legs were held in a rigid, scissored position and were difficult to move. There was spasticity of the upper extremities without cogwheeling. The strength was well preserved. The deep tendon reflexes were hyperactive in the upper extremities and unobtainable in the lower (except when the patient slept). There were prominent Babinski, Hoffman, and snout reflexes, but absent abdominals. There was excess drooling, reduced gag reflex, and poorly coordinated swallowing. There was no choreoathetosis, ataxia, or nystagmus. There were no apparent sensory deficits.

Because of recurrent urinary tract infections and difficulty in cleansing the perineum, an obturator neurectomy and adductor tendonotomy were performed. The patient has now been free of infection, after discontinuation of therapy, for over $1 \mathrm{yr}$.

M. U., the 8-yr-old brother of R. U., is the sixth child in the family. Pregnancy and delivery were normal with Apgar scores of 9 at 1 and $5 \mathrm{~min}$. Birthweight was $4000 \mathrm{~g}$ and length $50 \mathrm{~cm}$. His early development was entirely normal, and at $2 \frac{1}{2} \mathrm{yr}$ he walked, ran, and was speaking in short sentences. At this time, increasing clumsiness was noted, and a physical examination revealed hyperreflexia throughout, ankle clonus, spasticity of all four extremities with the lower greater than the upper, and Babinski, and Hoffman reflexes. At age $31 / 2$ a pneumoencephalogram and a four-vessel angiogram were normal, but the electroencephalogram was abnormal. The patient developed a mild febrile illness at this time which progressed to coma and severe seizure disorder. The liver enlarged greatly and a biopsy showed increased triadal fibrosis. The liver soon returned to normal size. A similar episode with hyperammonemia occurred $3 \mathrm{yr}$ later and resolved with supportive care and treatment of pneumonia. At age 3 , his height was below the third percentile and his weight was normal. Both have remained static since. The patient now has recurrent aspi- 
ration pneumonia due to his inability to handle his normal secretions.

The height $(103 \mathrm{~cm})$ and weight $(16.3 \mathrm{~g})$ were well below the third percentile and the head circumference $(51 \mathrm{~cm})$ was normal. The patient was friendly, outgoing, and communicative. The general physical examination was normal except for hirsutism. There was no hepatomegaly.

The neurologic examination revealed severe psychomotor retardation. He understood simple commands and used single words. Play was at the 2-yr-old level. The patient could support his weight, but stood on his toes with bent knees. The heel cords were short and scissoring occurred when sitting. The legs were spastic with 10-15 beats of clonus elicited at the ankles and knees. The reflexes were greatly increased with bilateral "spread" of reflexes in the lower extremities. There were Babinski, Hoffman, and snout reflexes, but no abdominal reflexes. There was no choreoathetosis, ataxia, or nystagmus. Drooling, a reduced gag reflex, and poorly coordinated swallowing was observed.

Laboratory data: The serum glutamic-oxaloacetic transaminase (82-167 IU/liter, normal, 6-36; SGOT), serum glutamic-pyruvate transaminase (121-274 IU/liter, normal, 10-45; SGPT), and creatinine phosphokinase (150-460 IU/liter, normal, 32-112), levels were all elevated while the uric acid (1.7-1.9 in R. U., 2.3-2.7 in M. U.) and the BUN (5-11) were reduced. When M. U. was in hyperammonemic coma, the SGOT (400) and SGPT (750) rose significantly, but returned to normal with clinical recovery. The electroencephalograms were abnormal due to generalized two to three cycle per second high voltage waves. The prothrombin time and partial thromboplastin time were minimally abnormal in $\mathbf{R}$ $\mathrm{U}$. and failed to respond to vitamin $\mathrm{K}$. There was mild hypochromic microcytic anemia. The following routine laboratory data were normal: other routine hematologic studies, routine urinalysis, serum electrolytes; calcium; phosphorus; magnesium; creatinine; blood sugar; alkaline phosphatase; aldolase; amylase; bilirubin; Murphy-Pattee (T4); serum protein and electrophoresis; quantitative immunoglobulins; and cholesterol and triglycerides. The electromyogram, nerve conduction, electrocardiogram, CSF (glucose, protein, cells) and roentgenograms of the chest, skull and an iv pyelogram (in R. U.) were all normal as well. A growth hormone level in R. U. obtained during surgery was $80 \mathrm{ng} / \mathrm{ml}$. Computerized axial tomography of the brain in $M$. U. at age 7 revealed cerebral atrophy with enlargement of the lateral ventricles and sulci.

Family history: The mother, now in her late thirties and the father, dead from an automobile accident, were normal and not known to be consanguineous. They came from the state of Durango in Mexico. Four living siblings and the remainder of the family are free of neurologic disease and have performed well in school.

\section{METHODS}

\section{CLINICAL STUDIES}

All studies were carried out on a clinical research ward except for the open liver biopsy which was performed while patient $R$. U. was under general anesthesia for corrective orthopedic surgery. Each procedure had explicit parental consent.

Blood and spinal fluid specimens were obtained $3 \mathrm{hr}$ after a meal containing one-third of the prescribed diet, unless otherwise stated. Each diet consisted of natural foods and contained an excess of nonprotein calories to minimize the use of amino acid carbon skeletons for energy production. Studies were done after the patient had been permitted to come to metabolic equilibrium on a diet for 1 week and when no intercurrent illness was present. Urinary amino acids were determined by the method of Shaw et al. (15), plasma and cerebrospinal fluid amino acids, by the method of Benson et al. (2). Ammonia was determined within 10 min of venipuncture by a modification of the method of Jacobs and Olthuis (8), in the UCLA Clinical Laboratory. Routine studies were performed in either the Clinical Research Center Core Laboratory or Clinical Laboratory according to standard techniques. Unless specifically indicated, normal laboratory values are those of the Clinical Laboratory or were determined by the authors, under circumstances comparable to those in the study.

\section{ENZYMATIC STUDIES}

Argininosuccinic acid lyase (EC 4.3.2.1.) was determined semiquantitatively as previously described (4). Except where indicated, red and white blood cell arginase (EC 3.5.3.1) was determined in heparinized specimens by a modification of the method of Tomlinson and Westall $(4,25)$. Blood specimens collected in ethylene diamine tetra-acetic acid or heparin, processed immediately or left at room temperature for $24 \mathrm{hr}$, all had the same arginase activity.

Control specimens were obtained from the hospital and research staff. Arginase activity tended to be relatively stable from day to day in the same individual.

The liver specimen was frozen at $-70^{\circ} \mathrm{C}$ within 5 min of biopsy. A small fresh sample was studied and revealed arginase deficiency of similar magnitude to that reported later in this paper. The urea cycle enzyme assays were carried out according to published methods (12).

\section{PATHOLOGY}

The liver biopsy was divided and a small portion quenched in isopentane cooled in liquid nitrogen, submitted to cryostat sectioning and evaluated histochemically with periodic acid-Schiff stain (with and without diastase digestion), oil red 0 for triglyceride, succinic dehydrogenase, $\mathrm{NADH}_{2}$-tetrazolium reductase, and for alkaline phosphatase. Hematoxylin and eosin, reticulin, and elastic van Giesen stains were performed on formalin fixed, paraffin embedded tissue. Other samples were fixed in $2.5 \%$ glutaraldehyde buffered with cacodylate, diced, dehydrated, and embedded in Epon 812. Examination of thin sections was performed with Siemens 1A electron microscope.

\section{RESULTS}

\section{CLINICAL STUDIES}

The initial urinary amino acid chromatogram which showed increased excretion of arginine (5-10 normal $(N))$, lysine $(2 N)$, cystine (2-7N) and ornithine (minimal) was one of atypical cystinuria. Because of our previous experience with this disorder, hyperargininemia was inferred and then confirmed by finding greatly increased levels of plasma arginine (3).

The patients were then placed on controlled protein intake and permitted to come to metabolic equilibrium for 1 week at which time plasma, urine, and CSF amino acids were measured. Plasma arginine (Table 1) was 4-5 times the upper limit of normal, but did not increase despite a tripling of the daily protein intake. Values for R. U. consistently exceeded those for M. U. Ornithine, another urea cycle intermediate, and lysine were in the normal range. Citrulline was high normal. Argininosuccinate was undetectable (normal). Glutamine which frequently rises in hyperammonemia was normal. Total urea levels were persistently reduced, but showed some response to increased protein intake. Other amino acid levels were normal.

Urinary amino acid excretion was grossly abnormal in both children and is best illustrated in M. U. (Table 2). Arginine excretion was at least 10 times normal on the $1 \mathrm{~g} / \mathrm{kg}$ diet and rose irregularly to as much as $\mathbf{3 7 5}$ times normal on the higher protein intakes. Ornithine, lysine, cystine, and other amino acids at least in large part sharing a common gastrointestinal and renal transport mechanism with arginine showed lesser, but still significant, increases in excretion as well. Glutamine was elevated but in proportion to many other amino acids as part of a mild generalized amino aciduria. The lower values in $R$. U. on the $2.5 \mathrm{~g}$ diet reflect 
Table 1. Urea cycle and related amino acids in the plasma $(\mu M)$

\begin{tabular}{|c|c|c|c|c|c|c|}
\hline & \multicolumn{5}{|c|}{ Protein intake ${ }^{1}$} & \multirow{3}{*}{$\begin{array}{c}\text { Normal } \\
\text { values }^{2}\end{array}$} \\
\hline & \multicolumn{3}{|c|}{ M. U. } & \multicolumn{2}{|c|}{ R. U. } & \\
\hline & 1.0 & 2.0 & 3.0 & 1.0 & 2.5 & \\
\hline Arginine & 637 & 591 & 677 & 786 & 913 & $21.2-151.0$ \\
\hline Citrulline & 52.5 & 37.7 & 45.7 & 39.4 & 57.6 & $12.0-55.4$ \\
\hline Ornithine & 46.1 & 38.6 & 40.1 & 74.9 & 95.3 & $29.5-126.0$ \\
\hline Lysine & 127 & 86.2 & 80.0 & 86.9 & 194 & $82.8-237.0$ \\
\hline Glutamine & 392 & 440 & 451 & 556 & 607 & $415.0-694.0$ \\
\hline Urea & $13.5^{3}$ & 14.7 & 18.4 & 15.5 & 20.3 & $20.0-30.0$ \\
\hline $\begin{array}{l}\text { Other amino } \\
\text { acids }\end{array}$ & Normal & Some low & Some low & Normal & Normal & \\
\hline
\end{tabular}

' Protein intake in $\mathrm{g} / \mathrm{kg}$ body weight/day. All specimens were collected $3 \mathrm{hr}$ after a meal containing one-third of the prescribed diet. One fasting sample was not distinguishable from the postprandial one.

${ }^{2}$ Dickinson et al. (7).

${ }^{3}$ Expressed as mg/dl.

Table 2. Urinary amino acid excretion on different diets

\begin{tabular}{|c|c|c|c|c|c|c|}
\hline & \multicolumn{5}{|c|}{ Protein intake' } & \multirow[b]{3}{*}{ Controls } \\
\hline & \multicolumn{3}{|c|}{ M. U. } & \multicolumn{2}{|c|}{ R. U. } & \\
\hline & 1.0 & 2.0 & 3.0 & 1.0 & $2.5^{2}$ & \\
\hline Arginine & $150-1150^{3}$ & $270-5600$ & $500-5400$ & $180-2100$ & $50-1250$ & ND-15 \\
\hline Ornithine & $75-265$ & $98-650$ & $195-700$ & $50-320$ & ND-150 & $\mathrm{ND}(<10)$ \\
\hline Lysine & $280-1400$ & $360-2050$ & $625-2450$ & $200-1700$ & $35-850$ & $15-80$ \\
\hline Cystine & $170-550$ & $265-750$ & $375-630$ & $160-600$ & $75-180$ & $20-50$ \\
\hline Glutamine & $455-850$ & $310-625$ & $315-750$ & $310-1100$ & $45-600$ & $100-400$ \\
\hline Other amino acids & \multicolumn{6}{|c|}{ Some slightly elevated } \\
\hline
\end{tabular}

' $\mathrm{g} / \mathrm{kg}$ body weight/day.

${ }^{2}$ Collected after diet had terminated for $12 \mathrm{hr}$. Values fell progressively toward normal on a protein-free diet.

${ }^{3}$ Expressed as $\mathrm{mg} / \mathrm{g}$ creatinine and quantitated by two-dimensional paper chromatography. Normal values from the Children's Hospital of Los Angeles.

${ }^{4}$ ND-not detectable.

the fact that specimens were collected successfully only after the protein challenge had been stopped for $12 \mathrm{hr}$ and she was on a protein-free diet. These fell off progressively and confirm urinary excretion as at least one means by which their body rids itself of excess ammonia as arginine. $\beta$-aminoisobutyric acid levels were 10-15 times normal in all specimens, far in excess of those normally seen by us in patients who excrete this compound on a genetic basis. This is paralleled by greatly increased urinary levels of uracil, uridine, and orotic acid (11) and may indicate greatly increased pyrimidine synthesis and breakdown with consequent accumulation of $\beta$-aminoisobutyric.

CSF was obtained when M. U. was eating $3 \mathrm{~g}$ of protein $/ \mathrm{kg} /$ day and when R. U. was eating both 1 and $2.5 \mathrm{~g}$. Except for the degree of glutamine elevation (1.5-6.0 times) the composition of all three samples was strikingly similar (Table 3 ). Arginine was increased 3-4-fold as expected, but, in addition, high levels of other amino acids were noted. Asparatate was 30-50N, ornithine $10-20 \mathrm{~N}$, glycine $10-15 \mathrm{~N}$, serine $5 \mathrm{~N}$, tryptophan 4-10N, methionine 3-6N, citrulline $N-4 N$, and glutamate $N-6 N$. Other amino acid levels were normal to slightly elevated. No particular pattern relative to known shared transport pathways was evident, as illustrated by the normal level of lysine and greatly elevated level of ornithine.

Ammonia was measured on multiple occasions in both siblings (Table 4). In general, when $1 \mathrm{~g}$ of protein was eaten and the patients were well, plasma ammonia was normal. As the protein intake was increased, plasma ammonia rose in both, but not in direct relation to the protein intake. On one occasion, while on a
Table 3. CSF amino acid levels

\begin{tabular}{|c|c|c|c|c|}
\hline & \multirow{2}{*}{$\frac{\text { M. U. }}{3.0^{\prime}}$} & \multicolumn{2}{|c|}{ R. U. } & \multirow[b]{2}{*}{ Controls ${ }^{2}$} \\
\hline & & 1.0 & 2.5 & \\
\hline Arginine & $69.5^{3}$ & 85.0 & 98.2 & $20.1 \pm 5.7$ \\
\hline Citrulline & 4.1 & Trace & 9.1 & $2.0 \pm 0.79$ \\
\hline Ornithine & 94.6 & 71.1 & 46.9 & $5.67 \pm 1.82$ \\
\hline Lysine & 29.4 & 15.0 & 14.4 & $18.5 \pm 6.84$ \\
\hline Aspartate & 28.5 & 50.3 & 30.0 & $0.90 \pm 0.53$ \\
\hline Threonine & 46.2 & 44.5 & 49.5 & $25.2 \pm 10.1$ \\
\hline Serine & 189 & 200 & 173 & $38.1 \pm 22.8$ \\
\hline Asparagine & $<7.1$ & 12.4 & 14.3 & \\
\hline Glutamate & 9.5 & 81.6 & Trace & $6.8 \pm 4.8$ \\
\hline Glutamine & 1094 & 718 & 3242 & $506 \pm 144$ \\
\hline Glycine & 104 & 115 & 85.2 & $6.7 \pm 1.3$ \\
\hline Alanine & 61.7 & 60.6 & 74.1 & $23.6 \pm 9.0$ \\
\hline Valine & 28.2 & 27.3 & 41.0 & $14.5 \pm 5.1$ \\
\hline Methionine & 12.1 & 11.4 & 26.1 & $2.7 \pm 1.3$ \\
\hline Isoleucine & 11.4 & 13.7 & 17.5 & $4.6 \pm 1.5$ \\
\hline Leucine & 19.1 & 22.9 & 25.9 & $10.7 \pm 3.8$ \\
\hline Tyrosine & 36.4 & 25.4 & 7.2 & $9.4 \pm 5.0$ \\
\hline Phenylalanine & 21.2 & 16.3 & 47.2 & $9.1 \pm 6.1$ \\
\hline Histidine & 35.4 & 46.4 & 62.5 & $12.9 \pm 4.5$ \\
\hline Tryptophan & 18.1 & 4.6 & 13.2 & $9.8 \pm 5.8$ \\
\hline
\end{tabular}

' Protein intake $\mathrm{g} / \mathrm{kg}$ body weight/day.

${ }^{2}$ Dickinson and Hamilton (6).

${ }^{3}$ Expressed as $\mu \mathrm{M}$. 
$1 \mathrm{~g}$ protein diet, R. U. became irritable and clinically hyperammonemic. This was confirmed by a plasma value of $240 \mu \mathrm{g} / \mathrm{dl}$.

Urinary urea in M. U. rose from $5.3 \pm 1.8 \mathrm{~g} / \mathrm{g}$ creatinine on the $1.0 \mathrm{~g}$ diet to $7.7 \pm 2.1$ on the $2.0 \mathrm{~g}$ diet and then to $10.2 \pm 1.3 \mathrm{on}$ the $3.0 \mathrm{~g}$ diet. No similar calculation could be accomplished in $\mathbf{R}$. U.

\section{ENZYME STUDIES}

Red blood cell arginase was invariably undetectable in lysates of the patients' red blood cells, a value $<0.5 \%$ of the normal mean (Table 5). Mixing experiments failed to demonstrate a soluble inhibitor.

Arginase activity in mixed white blood cells was undetectable in a total of three specimens from the two patients, a value less than 5\% of the lowest of four controls (Table 5).

Activity of the urea cycle enzymes was measured in a liver specimen obtained at laparotomy (Table 6). The low protein content was consistent with the histologic abnormalities (see above). The enzyme activity is expressed as units/mg protein. The arginase activity level was $1.6 \%$ of the normal mean, whereas the other four enzymes had activity within the normal range. The relatively lower activity of argininosuccinate synthase (53\% of normal) may be due to its known lability and the poor clinical state of the liver as shown by the histologic appearance and the elevated serum enzymes.

Table 4. Plasma ammonia levels with different daily protein intake

\begin{tabular}{ccc}
\hline Protein intake $^{2}$ & \multicolumn{2}{c}{ Ammonia level } \\
\cline { 1 - 3 } \cline { 3 - 3 } $\mathrm{g} / \mathrm{kg} /$ day & M. U. & R. U. \\
\hline 1.0 & 40 & $43 ; 240$ \\
2.0 & 132 & \\
2.5 & & $201 ; 228$ \\
3.0 & 64 &
\end{tabular}

' Expressed as $\mu \mathrm{g} / \mathrm{dl}$ of plasma. Normal level in adults and children is less than 50.

${ }^{2}$ Patients were maintained on this diet for at least 6 days before testing.

Table 5. Blood cell arginase activity in the U. family

\begin{tabular}{|c|c|c|}
\hline & Red cells & White cells' \\
\hline & $\begin{array}{c}\mu \text { moles } \\
\text { urea } / \mathrm{g} \mathrm{Hb} / \mathrm{hr}\end{array}$ & $\begin{array}{c}\mu \text { moles } \\
\text { urea } / \mathrm{mg} \text { protein } / \mathrm{hr}\end{array}$ \\
\hline M. U. & $<10$ & $<0.1$ \\
\hline R. U. & $<10$ & $<0.1,<0.1$ \\
\hline Mother & 225 & \\
\hline Sister & 460 & \\
\hline Sister & 500 & \\
\hline Sister & 400 & \\
\hline Controls & $957 \pm 206(643-1317)^{2}$ & $1.8,5.4,11.4,15.3$ \\
\hline
\end{tabular}

' Control values represent the mean of duplicate assays from a single specimen from four subjects.

${ }^{2}$ The mean $\pm S D$ with the range given in parentheses, for 21 controls.

\section{LIVER BIOPSY}

Routine paraffin embedded and cryostat sections revealed preservation of the lobular architecture. Subcapsular and eccentric periportal accummulations of lymphocytes and rare eosinophils were noted. Multifocal areas of hepatocyte swelling separated by more normal parenchyma were seen (Fig. 1). Such swollen "balloon" cells contained normal sized central nuclei. Periodic acidSchiff reactions for glycogen revealed a patchy increase in staining intensity which was removed after diastase preincubation (Fig. 2). Angular, atrophic Periodic acid-Schiff positive hepatocytes surrounded the central veins. Alkaline phosphatase revealed normal linear staining and reactivity of the bile canaliculi, inhibited by $2 \mathrm{~m} M$ L-tetramisole (Fig. 3). The Gomori acid phosphatase reaction, after $2 \mathrm{hr}$ incubation, revealed, positive Kupffer cell staining, but reduced activity in hepatocytes. Succinic dehydrogenase (SDH) reactivity was homogeneous throughout the liver cells, except for negative nuclear staining and reduced activity in severely ballooned hepatocytes. $\mathrm{NADH}_{2}$ tetrazolium reductase was

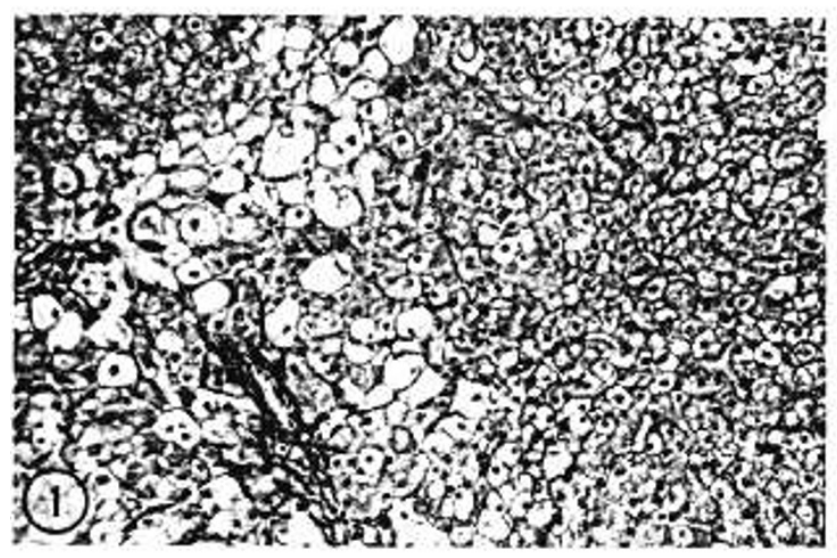

Fig. 1. Focal periportal balloon degeneration of hepatocytes. EosinVan Gieson stain. $\times 35$

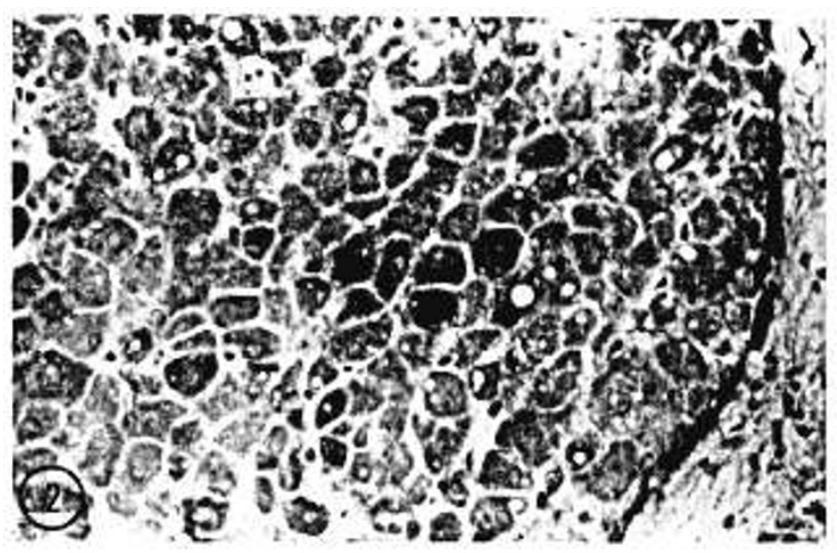

Fig. 2. Hepatocytes containing variable deposits of glycogen. Rare fat globules are noted. Periodic acid-Schiff reaction. $\times 40$.

Table 6. Urea cycle enzymes in the liver of $R . U$.

\begin{tabular}{lcccccc}
\hline & \multirow{2}{*}{$\begin{array}{c}\text { Liver protein content } \\
\mathrm{mg} / \mathrm{g} \text { wet weight }\end{array}$} & \multicolumn{1}{c}{ CPS } & OTC & AS & AL & ARG \\
\cline { 2 - 7 } & 74.3 & $1.72(90)$ & $43.1(98)$ & $0.33(53)$ & $1.31(88)$ & $9.02(1.6)$ \\
R. U. & 145 & $1.91 \pm 0.28$ & $44.2 \pm 7.8$ & $0.62 \pm 0.14$ & $1.49 \pm 0.27$ & $579 \pm 106$ \\
\hline Controls & & 145 &
\end{tabular}

${ }^{1}$ Expressed as units/mg protein with parentheses giving the percent of the normal mean. The controls represent a mean of eight surgical biopsies \pm SD. One unit is $1 \mu \mathrm{mole}$ of product formed per hour. CPS—carbamyl phosphate synthetase; OTC—ornithine transcarbamylase; AS—argininosuccinate synthetase; AL-argininosuccinate lyase; ARG-arginase.

${ }^{2}$ Short et al. (18). 
similar to the succinic dehydrogenase but swollen hepatocytes showed considerably less reactivity (Fig. 4). Intracellular lipid was not increased, although occasional hepatocytes revealed 2-4 u globules surrounded by microvesicular droplets.

Numerous hepatocytes were examined by electron microscopy. Nuclei were of normal configuration, contained peripheral chromatin condensation and normal appearing nucleoli. The cytoplasm contained a diffuse accumulation of glycogen mostly $\alpha$ rosettes, surrounding an apparent increase in small, round mitochondria. The mitochondrial matrix density was increased precluding detailed visualization of cristae. The endoplasmic reticulum was fragmented and in many zones, tubular dilatations of the ribosome studded membranes were seen (Fig. 5). There was no increase in numbers or size of lipid droplets. Lysomes within hepatocytes appeared diminished in number, a finding compatible with the greatly reduced acid phosphatase reaction. Autophagic vacuoles or membrane limited glycogen masses were absent.

\section{FAMILY STUDIES}

The mother and three normal siblings had red blood cell arginase levels $2 \mathrm{SD}$ or more below the mean for 21 control subjects and well below that of the lowest individual control (Table 5). Plasma arginine was in the high normal range (124 and $136 \mu \mathrm{M})$ in two of them on their usual modest protein intake.

\section{DISCUSSION}

Hyperargininemia due to arginase deficiency may now be considered to be an established disorder with certain common char-

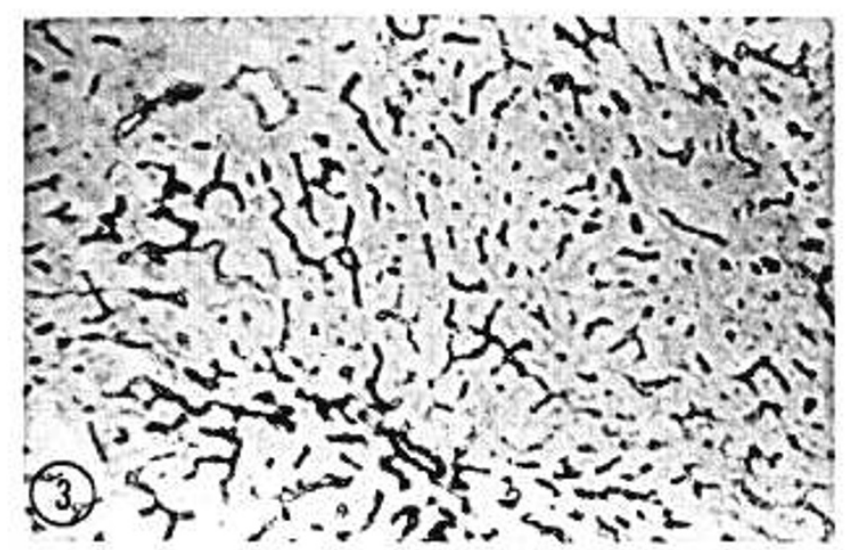

Fig. 3. Normal appearing linear pattern alkaline phosphatase positivity in the bile canalicular system. There is no evidence of lobular distortion. Gomori alkaline phosphatase reaction. $\times 40$.

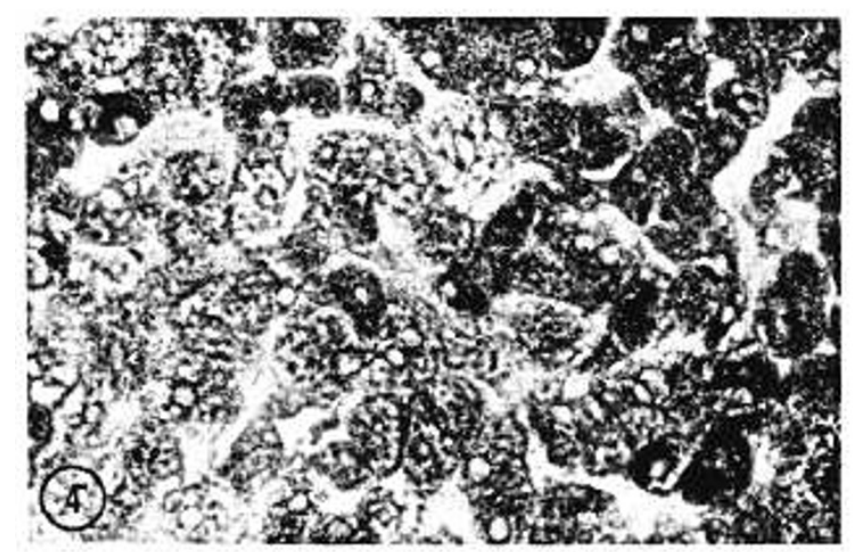

Fig. 4. Patchy dissolution and cavitation of the endoplasmic reticulum as revealed in the NADH tetrazolium reductase reaction. Note apparent increased reactivity in some cells and marked decrease in others. NADH tetrazolium reductase. $\times 45$. acteristics in the patients that have been described. These include: progressive loss of mental and motor skills; increasingly more severe spasticity and pyramidal tracts signs; abnormal spike and wave forms in the electroencephalogram; a relatively poor response of the elevated arginine levels in the plasma and CSF to dietary restriction; and no, or modest, elevations in plasma ammonia and urinary amino acids $(3,5,10,19,20,23,24,26)$. Ataxia $(19,23)$, choreoathetosis $(21)$, and periodic reversible acute clinical deterioration $(19,23, M$. U. in this report) have been reported as well. This course and the severity of the spasticity distinguish arginase deficiency clinically from the other disorders of the urea cycle and from other disorders of amino acid metabolism (17).

Although the deficiency of arginase had previously been demonstrated in red blood cells alone, the authors and others had inferred that the liver enzyme must be deficient as well $(3,19,24)$. The confirmation of this deficiency has been obtained in R. U. and by Michels and Beaudet (10) and has been shown to include arginase in mixed leucocytes and the stratum corneum (10).

The sex distribution, the half-normal levels of arginase in parents and siblings, and the half-normal levels in one of two grandparents establish the inheritance pattern of arginase deficiency as autosomal recessive $(3,5,19$; this report). The cause and effect relationship between the enzymatic defect and the disorder now appears virtually certain. In all five families, all ten of the retarded children have had a similar course and all have been arginase deficient. All 16 normal siblings have had normal or half-normal levels of the enzyme $(3,5,10,19)$.

The studies of plasma arginine levels in response to increases in the protein intake (Table 1) confirm previous data demonstrating the insensitivity of this chemical abnormality to protein restriction and implies that protein restriction alone is not a suitable treatment for this disorder $(3,19)$. The success of severe restriction, using a semisynthetic diet in bringing about striking clinical and biochemical improvement in two patients suggests that this mode of therapy may be successful and should be tried in all patients, as not all damage may be irreversible (19).

Elevated ammonia does occur in our patients and in most other patients with arginase deficiency at times, a finding underscored by the greatly elevated orotate and pyrimidine excretion in our patients (11). Because hyperammonemia is neither striking nor persistent, most authors agree that this is probably not the primary cause of the deterioration. In the past, mild cases of hyperammonemia have not been associated with relentless clinical deterioration.

Urinary amino acid studies revealed increasing excretion of arginine and to a lesser extent the other dibasic amino acids with increasing protein intake. This suggests that increased arginine excretion is one means by which excess ammonia is eliminated from the body in this condition. Subnormally increased urea excretion, increased pyrimidine excretion, and greatly increased excretion of guanidino compounds derived from arginine augment this (28). In theory, these measurements should allow for the characterization of the protein nitrogen economy in arginase deficiency as compared to normal, but the incomplete urinary collections so far obtained in these retarded patients precludes this.

The most remarkable clinical biochemical changes that occurred in our patients were in the CSF where arginine (as expected) and 15 to 16 other amino acids were elevated (Table 3). Aspartate, ornithine, and glycine were elevated to a remarkable extent. In the case of glycine, both the absolute levels and the CSF: plasma concentration ratio were similar to that seen in nonketotic hyperglycinemia (14). This distorted ratio has been proposed as an important pathogenic event in the latter disorder (14).

The delineation of pathognomonic features in a liver biopsy of a single case experience is unwarranted. The documentation of multifocal severe hydropic cellular change with variable residual glycogen, no increase in triglyceride, and decreased acid phosphatase reactivity indicative of diminished lysosome and/or autophagic vacuoles was noted. Such changes were not evidence of acute necrosis, but nuclear pyknosis was present in some cells. 


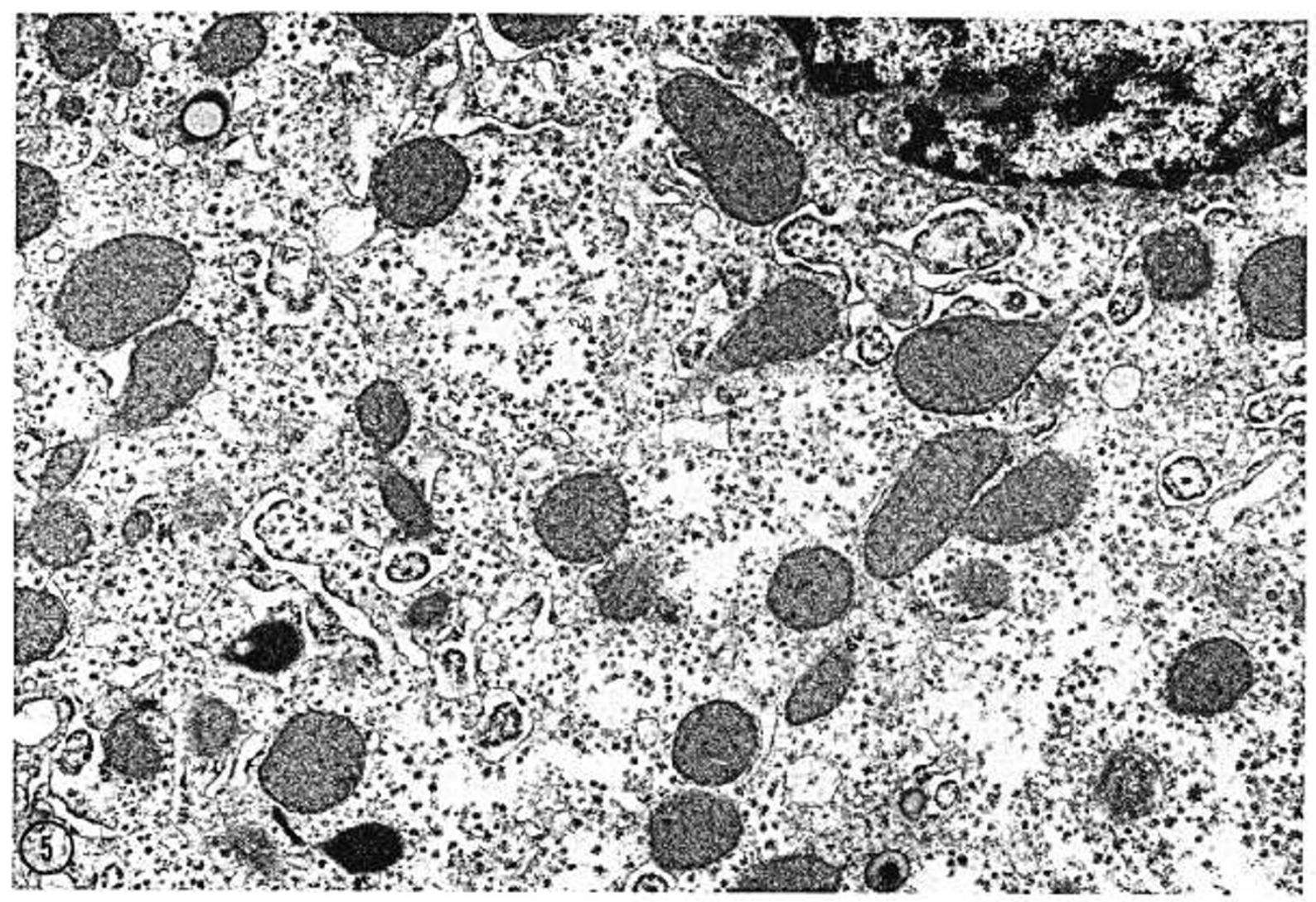

Fig. 5. Electron micrograph of moderately damaged hepatocyte revealing normal shape and disposition of mitochondria, slight increase in glycogen, and focal dilatations of endoplasmic reticulum with shedding of ribosomes. The nucleus appears unremarkable. Uranyl acetate. $\times 9000$.

Histochemical and electron microscopic studies demonstrated normal appearance of hepatic mitochondria, but an apparent increase in numbers of small, round mitochondria were noted in all hepatocytes. Megamitochondria or mitochondria with a floccular matrix as found in Reye's syndrome were not seen. No other reports of pathologic changes in arginase deficiency exist, but hepatic changes in patients with other urea cycle defects have revealed either no change (16), increased microvesicular fat (9) or multiple necrotic foci, with increased serum transaminase levels (1). Wick et al. (27) in a discussion of the variants of citrullinemia presented a case of hyperammonemia associated with diffuse hepatic fatty change and focal cell necrosis. Electron microscopic studies revealed concentric condensations of endoplasmic reticulum and increased electron density of the mitochondrial matrix, findings similar to those in the present case.

These patients emphasize the difficulty that may occur in making the clinical diagnosis of arginase deficiency. The abnormal amino acid excretion pattern may be construed as representing cystinuria coincidentally associated with spasticity and mental retardation. Moreover, the authors and others $(20,26)$ have shown that the urinary amino acid excretion pattern may be normal under some or almost all circumstances. We believe that all retarded or neurologically handicapped children with "cystinuria" and patients with progressive spasticity, seizures, and mental retardation should have the amino acid levels in plasma investigated.

Because of the difficulty in diagnosis, the true incidence of hyperargininemia is unknown. Finding a second family in a single institution within a short period of time supports our previous belief that this disorder may not be rare (3).

\section{REFERENCES AND NOTES}

1. Baumgartner, R., Scheidegger, S., Stalder, G., and Hottinger, A.: Argininbernsteinsaure Krankheit des Neugeborenen mit letalem Verlauf (neonatal death due to argininosuccinic aciduria). Helv. Paediatr. Acta, 1: 77 (1968). (1968).
2. Benson J. V. Jr., Gordon, M. J., and Patterson, J. A.: Accelerated chromatographic analyses of amino acids in physiological fluids containing glutamine and asparagine. Anal. Biochem., 18: 228 (1967).

3. Cederbaum, S. D., Shaw, K. N. F., and Valente, M.: Hyperargininemia. J. Pediat., 90: 569 (1977)

4. Cederbaum, S. D., Shaw, K. N. F., Valente, M., and Cotton, M. E.: Argininosuccinic aciduria. Am. J. Ment. Defic., 77: 395 (1973).

5. Columbo, J. P , Terhaggen, H. G., Lowenthal, A., Van Sande, M., and Rogers, S.: Argininemia. In F. A. Hommes and C. J. Van Den Berg: Inborn errors of metabolism. p. 239 (Academic Press, New York, 1973).

6. Dickinson, J. C., and Hamilton, P. B.: The free amino acids of human spinal fluid determined by ion exchange chromatography, J. Neurochem., 13: 1179 (1966).

7. Dickinson, J. C., Rosenblum, H. Q., and Hamilton, P. B.: Ion exchange chromatography of plasma amino acids of the newborn, Pediatrics, 36: 2 (1965).

8. Jacobs, H. A. M., and Olthuis, F. M. F. G.: A kinetic determination of ammonia in plasma. Clin. Chim. Acta, 43: 81 (1973).

9. Lewis, P. D., and Miller, A. L.: Argininosuccinic aciduria: case report with neuropathological findings. Brain, 93: 413 (1970).

10. Michaels V. V., and Beaudet, A. L.: Arginase desiciency in multiple tissues in argininemia. Clin. Gen. 13: 61 (1978).

11. Naylor, E. W., Cederbaum, S. D., Evans, J. E., Tieckelmann, H., and Guthrie, R.: Elevated urinary pyrimidine excretion in three patients with arginase deficiency, Amer. J. Hum. Gen., 29: 81a (1977).

12. Nuzum, C. T., and Snodgrass, P. J.: Multiple assays of the five urea cycle enzymes in human liver homogenates. In: S. Grisolia, R. Vaguena, and F. Major: The Urea Cycle. p. 325 (John Wiley and Sons, New York, 1971).

13. Peralta-Serrano, A.: Argininuria, consulsiones y oliogofrenia; un nuevo error urinato del metabolismo? Rev. Clin. Esp., 97: 176 (1965).

14. Perry, T. L., Urquhart, N., MacLean, J. E., Evans, M. E., Hansen, S., Davidson, G. F., Applegarth, D. A., McCloud, P. S., and Lock, J. E.: Nonketotic hyperglycinemia: glycine accummulation due to absence of glycine cleavage in brain. N. Engl. J. Med., 292: 1269 (1975).

15. Shaw, K. N. F., Gutenstein, M., Jacobs, E. E., and Blascovics, J. C.: Biochemical screening and monitoring of patients with phenylketonuria and variant forms of hyperphenylalaninemia. In: H. Bickel, F. P. Hudson, and L. I. Woolf: Phenylketonuria. p. 163 (George Thieme Verlag, Stuttgart, 1971).

16. Solitare, G. B., Shih, V. E., Nelligan, D. J., and Dolan, Jr., D. F: Argininosuccinic aciduria: clinical, biochemical, anatomical, and neuropathological observations. J. Ment. Defic. Res., 13: 153 (1969).

17. Shih, V. E., and Efron, M. L.: Urea cycle disorders, In: J. B. Stanbury, J. B. Wyngaarden, and D. S. Frederickson: The metabolic basis of inherited diseases. p. 370 (McGraw-Hill, New York, 1972).

18. Short, E. M., Conn, H. O., Snodgrass, P. J., Campbell, A. G. M., and Rosenberg, 
L. E: Evidence for X-linked dominant inheritance of ornithine transcarbamylase deficiency. N. Engl. J. Med., 288: 7 (1973).

19. Snyderman, S. E., Sansaricq, C., Cheu, W. J., Norton, P. M., and Phansalkar, S. V.: Argininemia. J. Pediat, 90: 563 (1977)

20. Terhaggen, H. G., Lavinha, F., Columbo, J. P., Van Sande, M., and Lowenthal, A.: Familial hyperargininemia, J. Genet. Hum., 20: 69 (1972).

21. Terhaggen, H. G., Lowenthal, A., Lavinha, F., and Columbo, J. P.: Familial hyperargininemia, Arch. Dis. in Childhood, 50: 57 (1975).

22. Terhaggen, H. G., Schwenk, A., Lowenthal, A., Van Sande, M., and Columbo, J. P.: Argininemia with arginase deficiency, Lancet, 2: 748 (1969).

23. Terhaggen, H. G., Schwenk, A., Lowenthal, A., Van Sande, M., and Columbo J. P.: Hyperargininamie mit arginasedefekt: Eine neue familiare stoffwechselstorung. I. Klinische befunde, Z. Kinderheilk, 107: 293 (1970).

24. Terhaggen, H. G., Schwenk, A., Lowenthal, A., Van Sande, M., and Columbo, J. P.: Hyperargininamie mit arginasedefekt: eine neue stoffwechselstorung. II. Biochemische untersuchungen, Z. Kinderheilk, 107: 313 (1970).

25. Tomlinson, S., and Westall, R. G.: Argininosuccinic aciduria. Argininosuccinase and arginase in human blood cells. Clin. Sci., 26: 261 (1964).

26. Van Sande, M., Terhaggen, H. G., Clara, R., Leroy, J. G., and Lowenthal, A.: Lysine-cystine pattern associated with neurological disorders, In N. A. J., Carson, and D. N. Raine, Inherited disorders of sulfur metabolism. p 85 (Churchill Livingstone, Edinburgh, 1971).

27. Wick, H., Bachmann, C., Baumgartner, R., Brechbuler, T., Columbo, J. P.,
Wiesmann, U., Mihatsch, M. J., and Ohnacker, H.: Variants of citrullinaemia. Arch. Dis. Childhood, 48: 636 (1973).

28. Wiechert, P., Mortelmans, J., Lavinha, F., Clara, R., Terhaggen, H. G., and Lowenthal, A.: Excretion of guanidinoderivatives in urine of hyperargininemic patients. J. Genet. Hum., 24: 61 (1976).

29. Presented in part at the annual meeting of the Society for Pediatric Research April 1976 (Pediat. Res., 10:363 (1976) and at the Fifth International Congress of Human Genetics, October 1976 (Excerpta Med., Intl. Cong. Ser., 397: 26 (1976).

30. The authors thank Drs. Vera Stanincova, Michel Philippart, and R. A. Pieter Kark for help in the ascertainment, diagnosis, and care of these patients; $\mathrm{Dr}$. George Joseph for translation of the German articles; Dr. George Popjak for support and encouragement; and Joan Blaskovics, Ruben Gambetta, and Morris Gutenstein for expert technical assistance.

31. This research was supported in part by the Mental Retardation Research Program, UCLA, the National Foundation-March of Dimes, Grant 6-125; and USPHS grants HD-04612, HD-06576, HD-05615, RR-00865, MCT-00911, AM-17299, and HD-11298.

32. Requests for reprints should be addressed to: S. D. Cederbaum, Mental Retardation Research Center, 760 Westwood Plaza, Los Angeles, CA 90024 (USA).

33. Received for publication January 3, 1978.

34. Accepted for publication July 19, 1978 